\title{
Effects of high pressure on texture and microstructure of sea bass (Dicentrarchus labrax L.) fillets
}

\author{
Romuald Chéret $^{1-2}$, Nicolas Chapleau ${ }^{1}$, Christine Delbarre-Ladrat ${ }^{2}$, Véronique Verrez-Bagnis $^{2}$, \\ Marie de Lamballerie ${ }^{1 *}$
}

\author{
${ }^{1}$ UMR CNRS 6144 GEPEA, ENITIAA, BP 82225, 44322, Nantes Cedex 3, France
}

${ }^{2}$ IFREMER, BP 21105, 44311 Nantes Cedex 3, France

*: Corresponding author : Phone: 33.2.51.78.54.65 Fax: 33.2.51.78.54.67 anton@enitiaa-nantes.fr

\begin{abstract}
High-pressure is an innovative non-thermal food preservation technology. We studied the effect of high-pressure treatment up to $500 \mathrm{MPa}-5 \mathrm{~min}$ on physical characteristics of sea bass fillets after 0,7 and 14 days of refrigerated storage. Color results exhibited an increase of lightness and a slight change of hue, which might be imperceptible in cooked fish. High-pressure treatment induced a decrease of exudation and water-holding capacity. Pressure treatment above $300 \mathrm{MPa}$ provoked fish hardness higher after storage than untreated sample, proving the ability of high-pressure to improve textural quality of chilled stored fish fillet. These assessments were corroborated with microstructure observations. We showed that high-pressure treatment at $500 \mathrm{MPa}$ allowed, after 7 days of storage, a total aerobic count equivalent to that of untreated fresh fish fillet to be obtained. Thus, high-pressure might be considered to be a technology able to improve safety and textural quality of fresh fish fillets.
\end{abstract}

Keywords: Fish; High-pressure; Texture Profile Analysis; Microstructure; Preservation 


\section{Introduction}

Among the various aspects that contribute to defining the quality of raw fish, freshness is one of the most important. Freshness of fish can be assessed thanks to organoleptic features. Generally, the muscle of fish is known to soften quickly during the post mortem storage in refrigerated conditions. One of the main features in appreciating fish is the texture. The appearance and the odour are also very important for consumers.

The muscle of fish has a very particular organization compared to meat, because it is constituted of the alternation of muscular sheets called myotomes separated and maintained by the connective tissue. Moreover, myotomes are composed by a large number of individual muscle fibres in a collagen matrix.

Post mortem softening of fish muscle is caused by the combination of two reactions: biochemical-induced by enzymatic degradation of myofibrils and collagen, and physical due to the separation of myotomes called "gaping".

After the fish dies, the period of rigor-mortis starts. The final quality of fish depends on this phase. Initially, the phenomenon of "gaping" proceeds and is characterised by the separation of the myotomes. This mechanical phenomenon is associated to the contraction of muscle fibres. The skeleton and the connective tissue support this contraction and keep muscle structure. The connective tissue resists until a certain pressure beyond which it weakens itself letting place to "gaping". "Gaping" is a consequence of the failure of fibres and tissue to connect the muscle blocks along the filet. (Lavety and others 1988; Bremner and Hallet 1985; Bremner 1992; Hallett and Bremner 1988). Then, for the period post mortem, many biochemical mechanisms will initiate the degradation of the muscle. These modifications lead to a reduction in hardness (Dunajsky 1979). Protein hydrolysis does not play a significant part. It was observed that the collagen fibres in the pericellular connective tissue were disintegrated. It has been shown in sea bass, that the changes occurring during 
post mortem degradation result in the weakening and disorganisation of the $\mathrm{Z}$ line structure, the deterioration of costamers, and a separation between filaments and I bands (Astier and others 1991; Papa and others 1996; Papa and others 1997). Several studies suggest that the gradual disintegration of the extracellular matrix structure in mainly responsible for tenderisation (Ando 1997; Bremner 1992; Montero 1997). The structural links and bonds of proteins are changed during the degradation. These changes are caused by enzymes: in most cases, a result of enzymatic reactions has been determinated, but not activities of the enzymes themselves (Rehbein 1997).

When the post mortem degenerative process takes place, the degradation of proteins creates ideal conditions for the growth of micro-organisms. In living fish, some microorganisms remain present on their skin and in the digestive system. After death, they are likely to contaminate the muscle of fish. The compounds formed by different degradations due to the micro-organisms release unpleasant odours. This phenomenon of degradation is dependent on storage temperature. Also, during storage, the color of flesh changes from a bluish translucent color to an opaque and cooked appearance.

Among the non-thermal processing techniques, high-pressure processing is of growing interest in food processing. Some products are already available in markets in Japan (fruits juices, jam, rice, seaweed), in the USA (avocado spread and oysters) and in Europe (orange juice in France and ham in Spain). Today, this technology is gaining popularity in the food industry.

Generally, products are subjected to high-pressure in the range of 100-1000 MPa. The main advantage of high-pressure is to inactivate pathogenic micro-organisms: so food shelflife can be prolonged. High-pressure processing for microbial decontamination has been extensively reviewed, but complete microbial inactivation is currently not possible (Knorr 1999; Smelt 1998). The advantage of high-pressure treatment over traditional thermal 
processing is the result in an almost complete retention of nutritional and organoleptic characteristics. However, chemical bonds of molecules are affected and that may induce modifications of water, proteins, polysaccharides and lipids. The main effect of high-pressure is to provoke changes in hydrophobic and electrostatic interactions with important consequences for the secondary, tertiary and quaternary structures in proteins. In muscle food, high-pressure treatment causes three main kinds of changes in muscle food: enzymatic, protein (mainly on myofibrils) and structural modifications. Pressure treatment of proteins can lead to significant conformational changes which influence functionality (Cheftel and Dumay 1997; Chapleau and de Lamballerie-Anton 2003). The mechanisms of these effects are not yet fully understood.

Recent studies showed that the high-pressure treatment could allow controlling or deactivating some enzymes involved in the degradation of fish muscle to modify the texture and to stabilise the color and the oxidation of the lipids (Angsupanich and Ledward 1998; Ashie and Simpson 1996; Oshima and others 1993).

The objective of this present study was to evaluate and understand the effect of the highpressure treatment on the different features that characterise the freshness of fish.

\section{Materials and methods}

\subsection{Preparation of the fish samples}

Fresh sea bass (Dicentrarchus labrax L.), 4 years old, average weight $325 \mathrm{~g}$ and length 300 $\mathrm{mm}$, were collected from a local aquaculture farm (Les Viviers du Gois, Beauvoir-sur-Mer, France) and brought back alive to the laboratory. The fish were slaughtered by decapitation, skinned and filleted in pre-rigor conditions. Only white muscles of the dorsal part of the fillet were collected to carry out experiments, measuring $50 \times 150 \mathrm{~mm}$ with a thickness of about 13 
mm. To take in account the fish variation, we used twelve fillets for each level of pressure: 0 , 100, 200, 300, 400 and $500 \mathrm{MPa}$.

\subsection{High-Pressure Processing}

110 High-pressure processing was carried out in a $3.5 \mathrm{~L}$ reactor unit (ACB Pressure Systems,

111 Nantes, France) equipped with temperature and pressure regulator device. Prior to pressure

112 processing, previously prepared sea bass fillets were vacuum packed individually in 113 polyethylene bag (La Bovida, France). The level of pressure (100, 200, 300, 400 and 500

$114 \mathrm{MPa})$ was reached at $3 \mathrm{MPa} / \mathrm{s}$, kept constant $5 \mathrm{~min}$, and then released quickly $(<1.5 \mathrm{~s})$.

115 Temperature of transmitting medium in the vessel was settled at $10^{\circ} \mathrm{C}\left( \pm 5^{\circ} \mathrm{C}\right)$ during pressure

116 treatment. Temperature of the cooling jacket which surrounded the pressure vessel was

117 controlled at $10{ }^{\circ} \mathrm{C}$ during pressure treatment. One thermocouple K-type $(0.3 \mathrm{~mm}$ diameter,

118 Omega, Stamford, CT, USA) positioned close to the sample, allowed the variation of

119 temperature during treatment to be followed. After pressure treatment, samples were stored on 120 ice (maximum $4 \mathrm{~h}$ ) until analysis.

\subsection{Storage of fillet}

Among 12 control or high-pressure treated fillets, four were analysed the very same day.

124 The eight other were stored at $4^{\circ} \mathrm{C}$, four were analysed 7 days later and four 14 days later.

125 Four fillets were used for all tests: color, exudation, WHC, texture and microstructure.

\subsection{Color measurements}

128 Color measurements were performed on intact fillets after pressure processing and/or 129 storage, using a Minolta CM-3500d (Minolta, Carrières-sur-Seine, France). Measures were 130 achieved in the referential CIE $1976 \mathrm{~L}^{*} \mathrm{a}^{*} \mathrm{~b}^{*}$, $\mathrm{L}^{*}$ denotes lightness on a 0 to 100 scale from 
131 black to white; $a^{*}$, corresponds to the indication of red when its value is positive and to green

132 when it is negative; $b^{*}$ corresponds to the indication of yellow when its value is positive and

133 to blue when it is negative. Measurements were repeated ten times on different positions of 134 four fish fillets.

\subsection{Exudation}

137 Exudation of fillet was determined by weighing samples prior to and after pressure 138 processing. The bags were unwrapped, surface drip was removed using filter paper, and fillets

139 were weighed. Each experimental value represented the mean of four determinations.

\subsection{Water-Holding Capacity}

142 The Water-Holding Capacity (WHC) was measured individually on coarsely chopped

143 filleted muscle. The samples $(10 \mathrm{~g})$ were transferred to centrifugation tubes and centrifuged at

$14410000 \mathrm{~g}$ for $15 \mathrm{~min}$ at $20^{\circ} \mathrm{C}$ (GR 20.22, Jouan, France). The WHC was determined as liquid 145 loss, and expressed by the percentage of weight of liquid that was retained in the fillets. Mean 146 values were calculated from four replicates.

\subsection{Texture profile analysis}

149 Texture measurements (according to Texture Profile Analysis defined by Bourne 1978)

150 were performed at room temperature with a texture testing machine (Lloyd Instruments

151 LR5K, United Kingdom) equipped with a sensor of $50 \mathrm{~N}$. Twelve cylindrical samples of 20

$152 \mathrm{~mm}$ in diameter were cut on the 4 dorsal muscles: 3 cylinders of a height of 11 to $14 \mathrm{~mm}$ were 153 sampled in the same way of the longitudinal orientation of the muscular fibres. Prior to 154 analysis, samples were allowed to reach room temperature $\left(20^{\circ} \mathrm{C}, 1 \mathrm{~h}\right)$. Each sample was 155 compressed between stainless steel plates (diameter $40 \mathrm{~mm}$ ) as shown on figure 1 . The texture 
measurement was composed by two consecutive compressions of $50 \%$ parallel to way of muscle fibre orientation, at a constant speed of $1 \mathrm{~mm} / \mathrm{s}$, with a delay of $30 \mathrm{~s}$ between the two compressions.

159 From the resulting force-time curve (figure 1), the following parameters were determined:

160 hardness corresponding to the maximum force required to compress the sample; cohesiveness,

161 extent to which the sample could be deformed prior to rupture $\left(\left(A_{3}+A_{4}\right) /\left(A_{1}+A_{2}\right)\right.$, where

$162 \mathrm{~A}_{1}+\mathrm{A}_{2}$ was the total energy required for the first compression and $\mathrm{A}_{3}+\mathrm{A}_{4}$ was the total energy

163 required for the second compression); springiness ability of sample to recover its original

164 form after the deforming force is removed $\left(\mathrm{L}_{2} / \mathrm{L}_{1}\right.$, were $\mathrm{L}_{1}$ was the lengthening of the first 165 compression and $\mathrm{L}_{2}$ was the lengthening of the second compression); gumminess was the

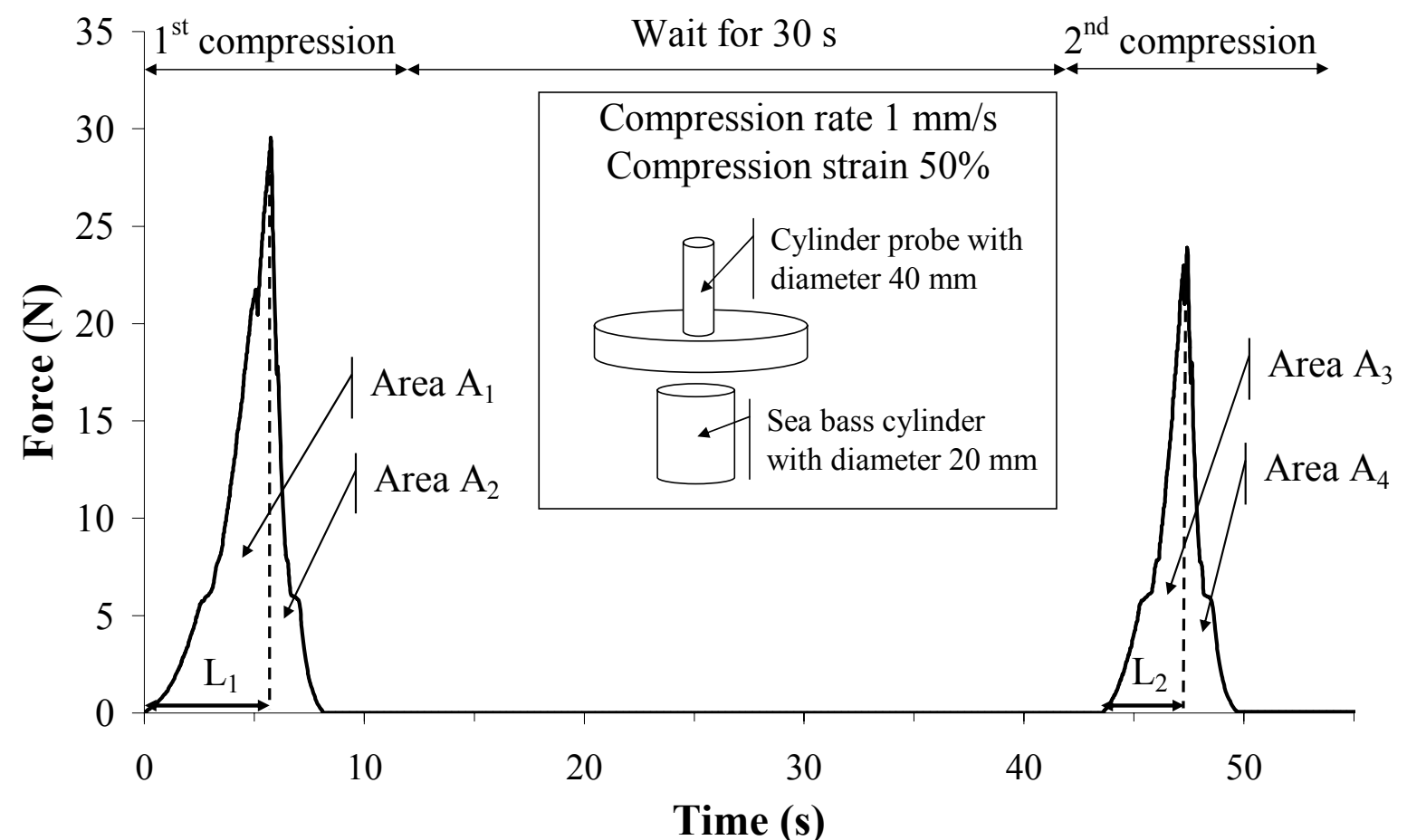

169 force needed to disintegrate a semisolid sample to a steady state of swallowing (hardness $\mathrm{x}$

170 cohesiveness); resilience was how well a product fights to regain its original position $\left(\mathrm{A}_{2} / \mathrm{A}_{1}\right.$,

171 where $A_{1}$ was the total energy required for compression of the first compression and $A_{2}$ was 
the total energy required for decompression of the first compression); chewiness, the work needed to chew a solid sample to a steady state of swallowing (springiness $\mathrm{x}$ gumminess).

\subsection{Microstructure analysis}

For each fillet analysed, two samples of $10 \times 5 \times 5 \mathrm{~mm}$ were cut transversally to the muscles fibres from the core of the fillet in the fleshiest part using a blade, then fixed in Carnoy's solutions $\left(60 \%\right.$ absolute ethanol, $30 \%$ chloroform and $10 \%$ glacial acetic acid, v/v) at $4{ }^{\circ} \mathrm{C}$. After $24 \mathrm{~h}$, the samples were brought to room temperature and dehydrated with several alcohol solutions, first in absolute ethanol for $2 \mathrm{~h}$ and then in 1-butanol for $2 \mathrm{~h}$ (repeated three times). Dehydrated samples were then cleared with toluene for $30 \mathrm{~min}$ (repeated three times) and embedded in paraffin at $56-58^{\circ} \mathrm{C}$. Samples were cut with a microtome Leica SM2000 (Leica, Germany) in $10 \mu \mathrm{m}$ thick slices. The sections were stained for $5 \mathrm{~min}$ in Orange $\mathrm{G}(0.5$ $\mathrm{g}$ of Orange $\mathrm{G}, 1 \mathrm{ml}$ acetic acid dissolved in $99 \mathrm{ml}$ distilled water and filtered at $0.45 \mu \mathrm{m}$ ). The sections were washed with distilled water and stained for $5 \mathrm{~min}$ in Aniline blue $(0.01 \mathrm{~g}$ of Aniline blue, $1 \mathrm{ml}$ acetic acid dissolved in $99 \mathrm{ml}$ distilled water and filtered at $0.45 \mu \mathrm{m})$. The stained samples were washed with distilled water before mounting with Eukitt (Labonord, France). This staining method stained the muscle proteins orange and collagen blue. The samples were examined in a microscope (Leica DML,Germany) fitted with a CCD RGB camera (MACC-C71, Sony, Japan) at 400× magnification.

\subsection{Microbiological analyses}

Aliquots $(10 \mathrm{~g})$ of fillets were prepared under sterile conditions and homogenised with a Stomacher for $30 \mathrm{~s}$ in $90 \mathrm{ml}$ sterile peptone water (BK 018, Biokar Diagnostics, Beauvais, France). Subsequently, a decimal dilution series of the homogenate was made, from which each 3 replicates were inoculated in depth plate $(1 \mathrm{ml})$ on plate count agar (BK 043, Biokar 
197 Diagnostics, Beauvais, France). The $\mathrm{CFU}$ formed after incubation at $30^{\circ} \mathrm{C}$ for $72 \mathrm{~h}$ was counted for dilutions setting 25 to $300 \mathrm{CFU}$. Results were expressed as the decimal logarithm of CFU per $g$ of fillet sample.

\subsection{Statistical analysis}

202 Statistical analysis was performed using a one-way analysis of variance according to the general linear model procedure with least-square means effects to determine significant differences between treatments. Multiple range tests were applied to determine which means were significantly different according to Fisher's Least Significant Differences (LSD). Significant differences were determined with $5 \%$ level of significance $(p<0.05)$ by Student's test. The vertical bars represent the standard deviation. Statistical analysis was carried out using Statgraphics plus version 5.0 software (Statistical Graphics Corp., Princeton NJ, USA).

\section{Results and discussion}

\subsection{Color}

Table 1 shows the evolution of lightness $\left(\mathrm{L}^{*}\right)$, red-green indice $\left(\mathrm{a}^{*}\right)$ and yellow-blue indice

$213\left(b^{*}\right)$ according to the pressure and to the time of storage. Before the treatment, the day the

214 fish dies, the muscle has a shiny, smooth, whitish and translucent appearance characterised 215 by a moderate value of $\mathrm{L}^{*}(34.19 \pm 1.51)$ and weak value of $\mathrm{a}^{*}(-2.48 \pm 0.46)$ and $216 b^{*}(0.39 \pm 0.92)$. The muscle of sea bass studied is a white muscle whose pigmentation is 217 bound to the presence of heme proteins, carotenoids and melanins. According to our results, 218 the storage of non-pressurised fillets led to an increase of $L^{*}$ value $(47.71 \pm 0.60)$ for storage 219 time of 7 days, then $L^{*}$ decreased $(42.56 \pm 1.90)$ for 14 days of storage. The indices of red220 green and yellow-blue remained almost constant during refrigerated storage. During storage, 221 the appearance of fish fillets became whiter and less grey. 
Table 1. $L * a * b *$ color parameters of sea bass fillets treated by high-pressure processing after 0,7 and 14 days at $4^{\circ} \mathrm{C}$.

\begin{tabular}{|c|c|c|c|c|c|c|c|}
\hline \multirow[b]{2}{*}{$\begin{array}{l}\text { Color } \\
\text { parameter }\end{array}$} & \multirow[b]{2}{*}{$\begin{array}{l}\text { Storage } \\
\text { time (day) }\end{array}$} & \multicolumn{6}{|c|}{ Pressure processing during 5 min } \\
\hline & & Control & $100 \mathrm{MPa}$ & $200 \mathrm{MPa}$ & $300 \mathrm{MPa}$ & $400 \mathrm{MPa}$ & $500 \mathrm{MPa}$ \\
\hline \multirow[t]{3}{*}{$\mathbf{L}^{*}$} & 0 & $34.19 \pm 1.51^{\mathrm{a} \alpha}$ & $37.45 \pm 1.52^{b \alpha}$ & $46.42 \pm 3.32^{c \alpha}$ & $61.54 \pm 1.61^{\mathrm{d} \alpha}$ & $66.39 \pm 1.20^{\mathrm{e} \alpha}$ & $71.30 \pm 1.49^{\mathrm{f} \alpha}$ \\
\hline & 7 & $47.71 \pm 0.60^{\mathrm{a} \beta}$ & $48.94 \pm 1.70^{\mathrm{a} \beta}$ & $54.32 \pm 1.94^{\mathrm{b} \beta}$ & $63.51 \pm 1.26^{\mathrm{c} \beta}$ & $72.04 \pm 1.50 \mathrm{~d} \beta$ & $70.24 \pm 1.59^{\mathrm{e} \alpha}$ \\
\hline & 14 & $42.56 \pm 1.90^{\mathrm{a} \gamma}$ & $45.12 \pm 1.31^{\mathrm{b} \gamma}$ & $51.63 \pm 3.35^{\mathrm{c \gamma}}$ & $60.83 \pm 1.65^{\mathrm{d} \alpha}$ & $65.55 \pm 1.95^{\mathrm{e} \alpha}$ & $70.25 \pm 2.10^{\mathrm{f} \alpha}$ \\
\hline \multirow[t]{3}{*}{$a^{*}$} & 0 & $-2.48 \pm 0.46^{\mathrm{a} \alpha}$ & $-3.75 \pm 0.38^{b \alpha}$ & $-5.23 \pm 0.60^{c \alpha}$ & $-5.88 \pm 0.57^{\mathrm{d} \alpha}$ & $-5.41 \pm 0.36^{\mathrm{c \alpha}}$ & $-4.79 \pm 0.38^{\mathrm{e} \alpha}$ \\
\hline & 7 & $-2.23 \pm 0.21^{\mathrm{a} \alpha}$ & $-2.89 \pm 0.15^{\mathrm{b} \beta}$ & $-4.05 \pm 0.28^{c \beta}$ & $-5.04 \pm 0.40 \mathrm{~d} \beta$ & $-4.85 \pm 0.40^{d \beta}$ & $-4.17 \pm 0.41^{c \beta}$ \\
\hline & 14 & $-3.33 \pm 0.28^{a \beta}$ & $-3.48 \pm 0.21^{\text {a } \gamma}$ & $-4.56 \pm 0.21^{\mathrm{b} \gamma}$ & $-5.76 \pm 0.43^{\mathrm{c} \alpha}$ & $-5.07 \pm 0.31 \mathrm{~d} \beta$ & $-4.41 \pm 0.44^{\mathrm{b} \beta}$ \\
\hline \multirow[t]{3}{*}{$\mathbf{b}^{*}$} & 0 & $0.39 \pm 0.92^{\mathrm{a} \alpha}$ & $-0.67 \pm 1.03^{\mathrm{a} \alpha}$ & $-2.25 \pm 1.00^{\mathrm{b} \alpha}$ & $0.16 \pm 1.64^{\mathrm{a} \alpha}$ & $2.58 \pm 1.51^{\mathrm{c} \alpha}$ & $4.74 \pm 1.66^{\mathrm{d} \alpha}$ \\
\hline & 7 & $-0.93 \pm 0.57 \mathrm{a} \beta$ & $-1.67 \pm 0.52 \mathrm{ab} \beta$ & $-2.65 \pm 1.01^{b c \alpha}$ & $-2.92 \pm 1.25^{\mathrm{c} \beta}$ & $0.58 \pm 1.48 \mathrm{~d} \beta$ & $2.99 \pm 1.37^{\mathrm{e} \beta}$ \\
\hline & 14 & $0.78 \pm 1.14^{\mathrm{ab} \alpha}$ & $-0.43 \pm 0.79^{\text {ac } \alpha}$ & $-0.71 \pm 1.06^{\mathrm{c} \beta}$ & $-1.33 \pm 1.37^{\mathrm{c \gamma}}$ & $1.51 \pm 2.01^{\mathrm{b} \alpha \beta}$ & $4.75 \pm 1.81^{\mathrm{d} \alpha}$ \\
\hline \multirow[t]{3}{*}{ h } & 0 & $171.45 \pm 21.50^{\text {a } a}$ & $190.65 \pm 15.85^{\mathrm{bc} \alpha}$ & $203.19 \pm 10.65^{\mathrm{c} \alpha}$ & $177.98 \pm 15.53^{\mathrm{ab} \alpha}$ & $155.62 \pm 12.88^{\mathrm{d} \alpha}$ & $136.60 \pm 9.30^{\mathrm{e} \alpha}$ \\
\hline & 7 & $201.66 \pm 12.96^{\mathrm{a} \beta}$ & $209.63 \pm 8.18^{\mathrm{a} \beta}$ & $212.47 \pm 11.83^{\mathrm{a} \alpha}$ & $209.71 \pm 10.85^{\mathrm{a} \beta}$ & $175.85 \pm 18.32^{\mathrm{b} \beta}$ & $145.93 \pm 12.82^{\mathrm{c} \alpha}$ \\
\hline & 14 & $168.25 \pm 16.14^{\mathrm{a} a}$ & $187.08 \pm 12.51^{\mathrm{b} \alpha}$ & $188.63 \pm 12.85^{\mathrm{b} \beta}$ & $192.07 \pm 12.35^{\mathrm{ba}}$ & $164.96 \pm 18.61^{\mathrm{a} \alpha \beta}$ & $134.58 \pm 12.30^{\mathrm{c} \beta}$ \\
\hline \multirow[t]{3}{*}{$C^{*}$} & 0 & $2.68 \pm 0.47^{\mathrm{a} a}$ & $3.94 \pm 0.21^{\mathrm{b} \alpha}$ & $5.78 \pm 0.51^{\mathrm{ca}}$ & $6.08 \pm 0.57^{\mathrm{c} \alpha}$ & $6.13 \pm 0.72^{c \alpha}$ & $6.82 \pm 1.25^{\mathrm{d} \alpha} \beta$ \\
\hline & 7 & $2.48 \pm 0.13^{\mathrm{a} a}$ & $3.37 \pm 0.23^{\mathrm{b} \beta}$ & $4.93 \pm 0.36^{\mathrm{c} \beta}$ & $5.90 \pm 0.76^{\mathrm{d} \alpha}$ & $5.08 \pm 0.37^{\mathrm{c} \beta}$ & $5.24 \pm 0.84^{\mathrm{c} \beta}$ \\
\hline & 14 & $3.55 \pm 0.47 \mathrm{a}$ & $3.58 \pm 2.11^{\mathrm{a} \gamma}$ & $4.72 \pm 0.22^{\mathrm{b} \beta}$ & $6.03 \pm 0.61^{\mathrm{cd} \alpha}$ & $5.58 \pm 0.75^{\mathrm{c} \alpha \beta}$ & $6.61 \pm 0.84^{\mathrm{d} \alpha}$ \\
\hline
\end{tabular}

All values were means \pm standard deviation of ten values

Same letters $(\mathrm{a}, \mathrm{b}, \mathrm{c}, \mathrm{d})$ in the same row indicate no significant differences between means $(p \leq 0.05)$

Same symbol $(\alpha, \beta, \gamma)$ in the same column indicate no significant differences between means $(p \leq 0.05)$ 
Whatever pressure level, application of pressure on fillet induces an increase of $\mathrm{L}^{*}$ value.

225 From $300 \mathrm{MPa}, \mathrm{L}^{*}$ is almost two times higher than the untreated sample: the fish looks like it 226 is cooked. For the untreated sample and $100 \mathrm{MPa}$ and $200 \mathrm{MPa}$ samples, $\mathrm{L}^{*}$ value changes in 227 a significant way with the time of storage: it is higher on day 7 and decreases between days 7 and 14, but final day 14 value is higher than for the untreated sample. However, from 300 $\mathrm{MPa}$, pressure-induced modifications of $\mathrm{L}^{*}$ value change very slightly during storage. Thus 230 lightness of sea bass fillet raises under high-pressure treatment and from $300 \mathrm{MPa}$, the 231 increase is particularly important but does not change with time storage.

232 Table 1 shows a* changes with high-pressure level, from -2.48 for untreated sample to -4.79 for $500 \mathrm{MPa}$, and $\mathrm{b}^{*}$ changes in diverse ways around its initial value 0.39 . Changes of hue are better described considering $\lambda$ value in CIE Yxy system. We noticed in table 1 that main wavelength increases in a significant way to greenish and almost yellowish at $400 \mathrm{MPa}$ : hue 236 changes from bluish to greenish and almost yellowish at $500 \mathrm{MPa}$. Of course fish appearances is neither blue nor green but these color terms indicate the trend of white translucent color.

238 Changes of hue characteristics are not modified during storage. These results are in accordance with Ashie and Simpson (1996), who put in evidence an increase of L* from 0 to $300 \mathrm{MPa}$ in bluefish, and with Oshima and others 1992).

241 The fish fillet color is linked with heme based pigment, physical structure of muscle and 242 amount of unbound water which influences light scattering. As sea bass is a white fish, we 243 can suppose that changes of pigments under high-pressure treatment are of minor importance,

244 so we can attribute these changes to modifications of protein matrix. In the same way, 245 evolution of color during storage can be associated with enzymatic and non enzymatic 246 reactions resulting in degradation of myofibrillar proteins and disorganisation of myofibrils 247 (Haard, 1992; Jiang, 2000). 


\section{2. Exudation during storage}

250 Figure 2 shows the evolution of fish fillet natural exudation with pressure treatment for the 3 251 storage times. Whatever pressure level, high-pressure treatment does not induce any variation 252 of exudation first day. However considering results of exudation after storage, we can 253 consider two groups. For samples treated at $100 \mathrm{MPa}$ and $200 \mathrm{MPa}$ exudation increases two 254 times the seventh day and four times the fourteenth day. For samples treated at $300 \mathrm{MPa}, 400$ $255 \mathrm{MPa}$ and $500 \mathrm{MPa}$, exudation changes very few during storage. Then from $300 \mathrm{MPa}$ yield is 256 improved the seventh and the fourteenth day storage. The increase of exudation with storage 257 time for control, $100 \mathrm{MPa}$ and $200 \mathrm{MPa}$ can be related with enzymatic and microbiological 258 degradation of muscle which modifies muscle structure and leads to an important water 259 release. High-pressure treatment above $200 \mathrm{MPa}$ induces an irreversible denaturation of 260 proteins than can reach a gelation. This phenomenon allows better natural water retention. 261 High-pressure treatment above $200 \mathrm{MPa}$ also induces modifications of proteases activity then 262 causing indirectly an increase of water retention.

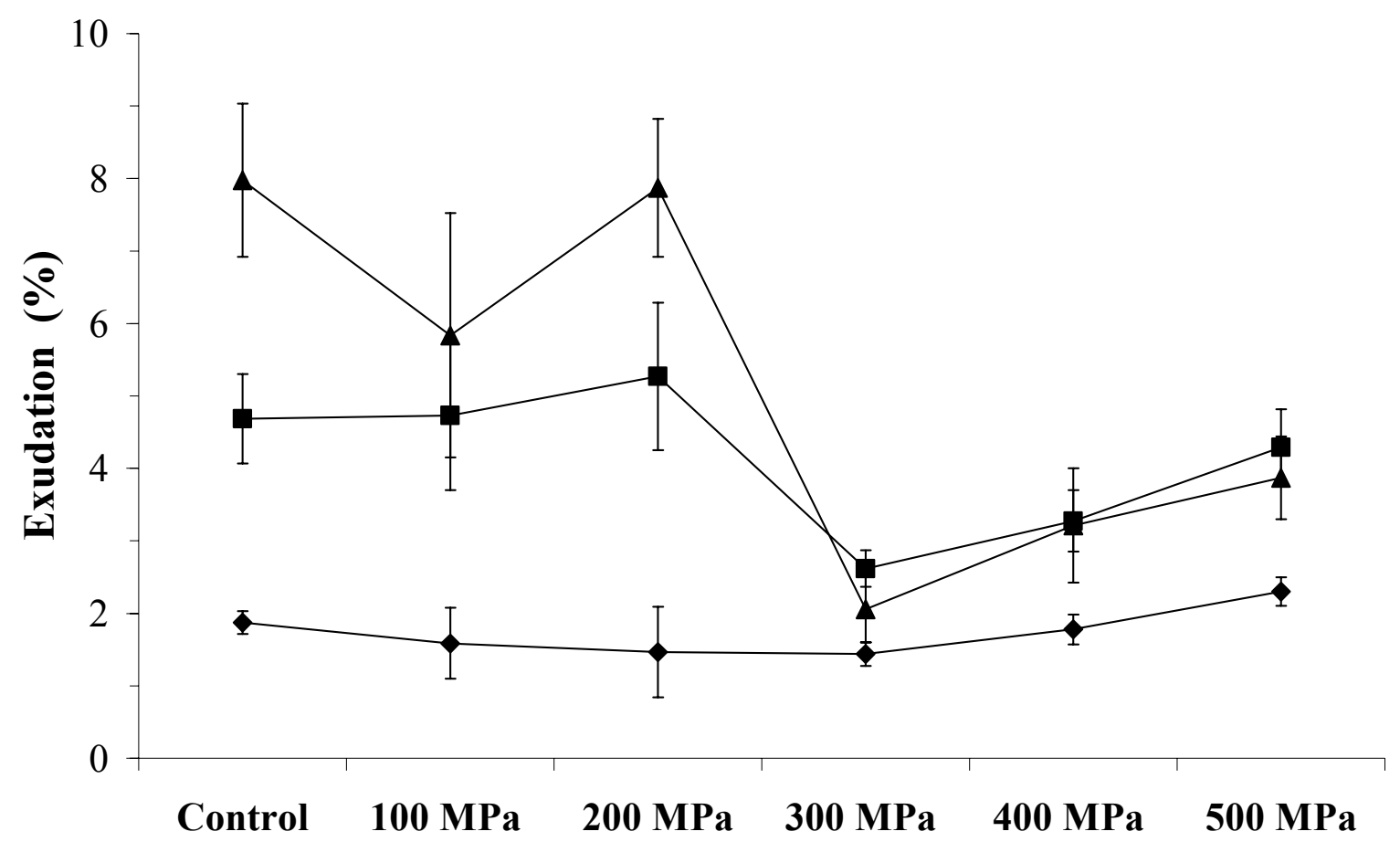


Fig. 2. Evolution of sea bass fillet exudation treated by high-pressure $(5 \mathrm{~min})$ after storage at $4^{\circ} \mathrm{C}$ during $0(\diamond), 7(\square)$ and $14(\Delta)$ days.

\subsection{Water-Holding Capacity (WHC)}

268 The evolution of WHC with pressure applied is presented figure 3. WHC evaluation requires 269 a grinding and a centrifugation producing a forced water release. For untreated sample, 270 storage induced a significant increase of WHC. As we previously underscored the increase of 271 natural exudation with time of storage, it might appear an opposite result. In fact, WHC 272 evaluate the ability of proteins to bind water after grinding. This particular property increases 273 with storage. Figure 4 also shows that WHC decreases when pressure level increases, and that 274 time of storage has no more a significant effect when sample is pressurized. Bremmer (2002) 275 put in evidence this decrease of WHC in sole and Pollack, so our results are accordance 276 because sea bass can also be considered as a non fat fish. Grinding before WHC evaluation 277 destroys previously cited protein gel due to high-pressure treatment, and denatured proteins 278 are no more able to bind intrinsic water.

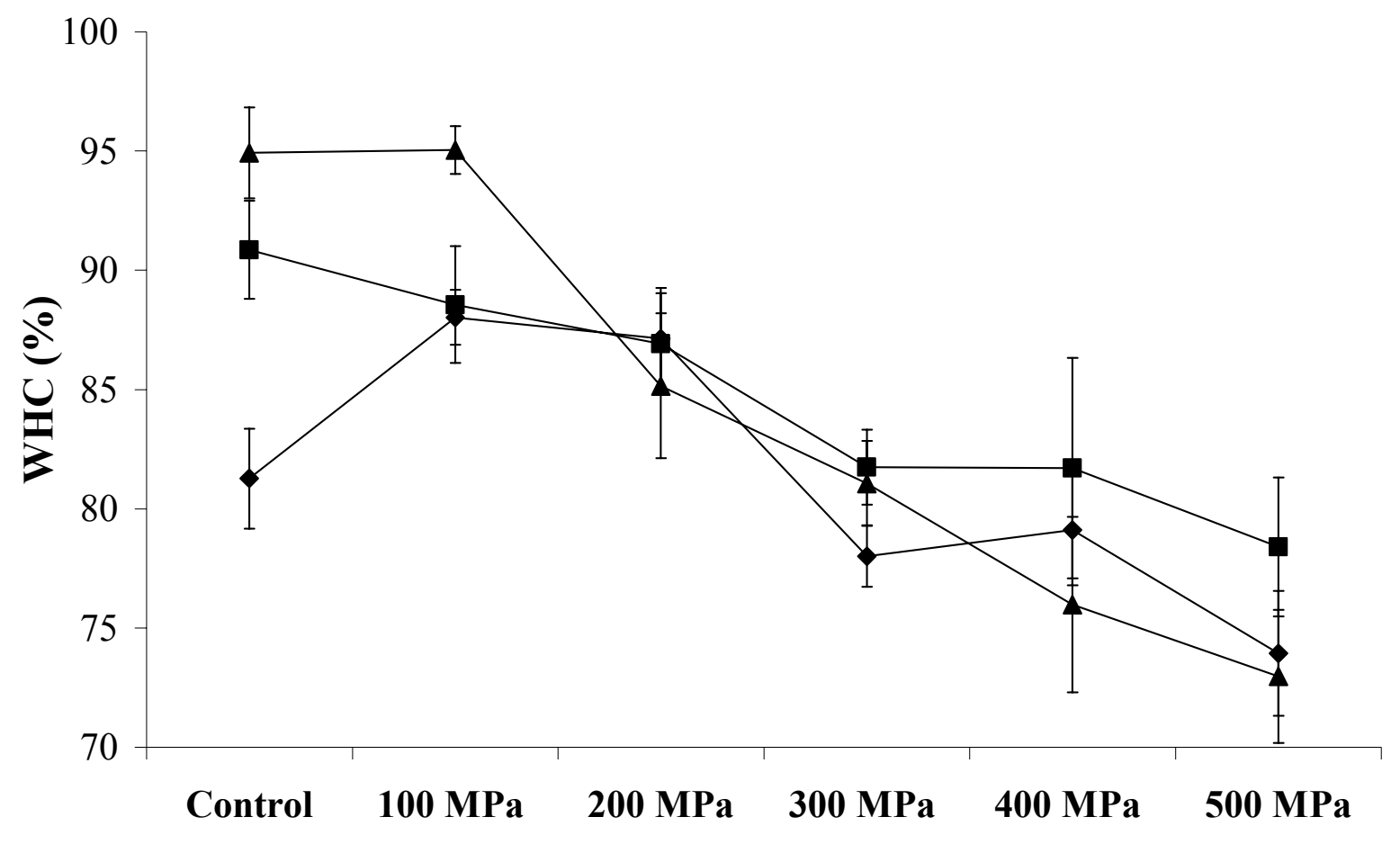



capacity of sea bass fillets treated by high-pressure ( $5 \mathrm{~min}$ ).

Denaturation of myofibrillar proteins, which are mainly involved in WHC, increases with 284 increasing pressure. Thus, it is normal to observe a decrease of WHC with increasing 285 pressure.

\subsection{Modification of texture induced by high-pressure and ageing}

Texture Profile Analysis (TPA) was carried out to determinate the effect of pressure treatment and storage for 0,7 and 14 days on the texture of fish muscle. The results of textural measurements are summarized in table 2: hardness, cohesiveness, springiness, gumminess, 291 resilience and chewiness.

292 For untreated sample, all six texture criteria decrease in a significant way between the first 293 and the seventh day of storage, showing that muscle becomes softer. During storage at $4^{\circ} \mathrm{C}$, 294 enzymatic degradation induces many physical mechanisms, among them the gaping, which 295 contribute to muscle tenderization (Dunajsky, 1979). Proteases implied are mainly calpains, 296 cathepsins and collagenases. Calpains and cathepsins act on the myofibrillar proteins and 297 promote myofibril fragility, and collagenases act on the connective tissue and contribute to 298 gaping (Montero, 1997). 


\begin{tabular}{|c|c|c|c|c|c|c|c|}
\hline \multirow[b]{2}{*}{$\begin{array}{l}\text { TPA } \\
\text { parameter }\end{array}$} & \multirow[b]{2}{*}{$\begin{array}{l}\text { Storage time } \\
\text { (day) }\end{array}$} & \multirow[b]{2}{*}{ Control } & \multicolumn{5}{|c|}{ Pressure processing during $5 \mathrm{~min}$} \\
\hline & & & $100 \mathrm{MPa}$ & $200 \mathrm{MPa}$ & $300 \mathrm{MPa}$ & $400 \mathrm{MPa}$ & $500 \mathrm{MPa}$ \\
\hline \multirow[t]{3}{*}{ Hardness } & 0 & $29.82 \pm 2.13^{\mathrm{a} \alpha}$ & $24.17 \pm 3.99^{\mathrm{bc} \alpha}$ & $22.78 \pm 2.86^{\mathrm{b} \alpha}$ & $26.04 \pm 3.89^{\mathrm{c} \alpha}$ & $31.24 \pm 2.24^{\mathrm{a} \alpha}$ & $32.70 \pm 4.70^{\mathrm{a} \alpha \beta}$ \\
\hline & 7 & $25.53 \pm 4.32^{\mathrm{a} \beta}$ & $27.50 \pm 3.49^{\mathrm{a} \alpha}$ & $20.44 \pm 2.72^{b \alpha}$ & $26.39 \pm 2.22^{\mathrm{a \alpha}}$ & $38.04 \pm 2.76^{\mathrm{c} \beta}$ & $33.14 \pm 4.00^{\mathrm{d} \beta}$ \\
\hline & 14 & $25.25 \pm 3.50^{\mathrm{a} \beta}$ & $24.55 \pm 4.49^{\mathrm{a} \alpha}$ & $23.26 \pm 3.85^{\mathrm{ab} \alpha}$ & $21.09 \pm 1.51^{\mathrm{b \beta}}$ & $35.01 \pm 2.94^{\mathrm{c \gamma}}$ & $28.93 \pm 3.38^{c \alpha}$ \\
\hline \multirow[t]{3}{*}{ Cohesiveness } & 0 & $0.52 \pm 0.04^{\mathrm{a} \alpha}$ & $0.53 \pm 0.06^{\mathrm{a} \alpha}$ & $0.55 \pm 0.03$ ab $\alpha$ & $0.56 \pm 0.03^{\mathrm{ab} \alpha}$ & $0.55 \pm 0.08^{\mathrm{ab} \alpha}$ & $0.58 \pm 0.04^{\mathrm{b} \alpha}$ \\
\hline & 7 & $0.25 \pm 0.04^{\mathrm{a} \beta}$ & $0.42 \pm 0.05^{\text {bcd } \beta}$ & $0.41 \pm 0.04^{\mathrm{bc} \beta}$ & $0.40 \pm 0.05^{\mathrm{b} \beta}$ & $0.45 \pm 0.07^{\mathrm{cd} \beta}$ & $0.46 \pm 0.05^{\mathrm{d} \beta}$ \\
\hline & 14 & $0.30 \pm 0.04^{\mathrm{a} \gamma}$ & $0.36 \pm 0.04^{\text {by }}$ & $0.40 \pm 0.04^{\mathrm{bc} \beta}$ & $0.43 \pm 0.06^{\mathrm{c} \beta}$ & $0.50 \pm 0.06^{\mathrm{d} \alpha \beta}$ & $0.56 \pm 0.03^{\mathrm{e} \alpha}$ \\
\hline \multirow[t]{3}{*}{ Springiness } & 0 & $0.69 \pm 0.04^{\mathrm{a \alpha}}$ & $0.63 \pm 0.05^{\mathrm{bc} \alpha}$ & $0.61 \pm 0.04^{\mathrm{b} \alpha}$ & $0.65 \pm 0.04^{\mathrm{cd} \alpha}$ & $0.69 \pm 0.04^{\mathrm{ad} \alpha}$ & $0.74 \pm 0.06^{\mathrm{e} \alpha}$ \\
\hline & 7 & $0.51 \pm 0.03^{\mathrm{a} \beta}$ & $0.55 \pm 0.06^{\mathrm{ab} \beta}$ & $0.59 \pm 0.05^{\mathrm{bc} \alpha}$ & $0.54 \pm 0.05^{\mathrm{ab} \beta}$ & $0.57 \pm 0.06^{\mathrm{b} \beta}$ & $0.62 \pm 0.03^{\mathrm{c} \beta}$ \\
\hline & 14 & $0.47 \pm 0.04^{\mathrm{a} \gamma}$ & $0.51 \pm 0.05^{\mathrm{b} \beta}$ & $0.57 \pm 0.05^{\mathrm{cd} \alpha}$ & $0.54 \pm 0.05^{\mathrm{bc} \beta}$ & $0.60 \pm 0.03^{\mathrm{d} \beta}$ & $0.66 \pm 0.04^{\mathrm{e} \beta}$ \\
\hline \multirow[t]{3}{*}{ Gumminess } & 0 & $15.32 \pm 1.22^{\mathrm{ab} \alpha}$ & $12.67 \pm 1.99^{\operatorname{cd} \alpha}$ & $12.60 \pm 1.52^{c \alpha}$ & $14.49 \pm 1.92^{\mathrm{ad} \alpha}$ & $17.19 \pm 3.05^{\text {be } \alpha}$ & $18.97 \pm 2.33^{\mathrm{e} \alpha}$ \\
\hline & 7 & $6.35 \pm 1.47^{\mathrm{a} \beta}$ & $11.39 \pm 1.23^{b \alpha}$ & $8.40 \pm 1.25^{\mathrm{c} \beta}$ & $10.46 \pm 1.34^{\mathrm{b} \beta}$ & $17.07 \pm 2.31^{\mathrm{d} \alpha}$ & $15.21 \pm 2.35^{\mathrm{e} \beta}$ \\
\hline & 14 & $7.51 \pm 1.53^{\mathrm{a} \beta}$ & $8.91 \pm 2.10^{\mathrm{ab} \beta}$ & $9.36 \pm 2.00^{\mathrm{b} \beta}$ & $9.13 \pm 1.42^{\mathrm{ab} \beta}$ & $17.44 \pm 2.06^{\mathrm{c} \alpha}$ & $16.24 \pm 1.16^{\mathrm{c} \beta}$ \\
\hline \multirow[t]{3}{*}{ Resilience } & 0 & $0.34 \pm 0.04^{\mathrm{ab} \alpha}$ & $0.35 \pm 0.04^{b \alpha}$ & $0.32 \pm 0.04^{\mathrm{abc} \alpha}$ & $0.31 \pm 0.02^{\mathrm{bc} \alpha}$ & $0.30 \pm 0.06^{\mathrm{c} \alpha}$ & $0.32 \pm 0.03^{\mathrm{abc} \alpha}$ \\
\hline & 7 & $0.13 \pm 0.02^{\mathrm{a} \beta}$ & $0.23 \pm 0.04^{\mathrm{b} \beta}$ & $0.18 \pm 0.02^{\mathrm{c} \beta}$ & $0.18 \pm 0.03^{\mathrm{c} \beta}$ & $0.22 \pm 0.04^{\mathrm{bd} \beta}$ & $0.20 \pm 0.03^{\mathrm{cd} \beta}$ \\
\hline & 14 & $0.14 \pm 0.02^{a \beta}$ & $0.19 \pm 0.03^{\mathrm{b} \gamma}$ & $0.17 \pm 0.03^{\mathrm{b} \beta}$ & $0.18 \pm 0.03^{\mathrm{b} \beta}$ & $0.23 \pm 0.03^{\mathrm{c} \beta}$ & $0.25 \pm 0.02^{\mathrm{cr}}$ \\
\hline \multirow[t]{3}{*}{ Chewiness } & 0 & $10.62 \pm 1.12^{\mathrm{ab} \alpha}$ & $8.04 \pm 1.58^{\mathrm{cd} \alpha}$ & $7.68 \pm 1.15^{\mathrm{c} \alpha}$ & $9.45 \pm 1.31$ bd $\alpha$ & $11.92 \pm 2.46^{\mathrm{b} \alpha}$ & $14.11 \pm 2.12^{\mathrm{e} \alpha}$ \\
\hline & 7 & $3.27 \pm 0.92^{\mathrm{a} \beta}$ & $6.24 \pm 1.06^{\mathrm{b} \beta}$ & $4.97 \pm 1.00^{\mathrm{b} \beta}$ & $5.70 \pm 0.91^{\mathrm{b} \beta}$ & $9.84 \pm 1.93^{\mathrm{c} \beta}$ & $9.50 \pm 1.53^{\mathrm{c} \beta}$ \\
\hline & 14 & $3.49 \pm 0.69 \mathrm{a}$ & $4.57 \pm 1.24^{\mathrm{b \gamma}}$ & $5.23 \pm 0.94^{\mathrm{b} \beta}$ & $4.92 \pm 1.02^{\mathrm{b} \beta}$ & $10.52 \pm 1.50^{c \alpha \beta}$ & $10.63 \pm 0.31^{\mathrm{c} \beta}$ \\
\hline
\end{tabular}

For each criterion, all values were means \pm standard deviation of ten values

Same letter $(\mathrm{a}, \mathrm{b}, \mathrm{c}, \mathrm{d}, \mathrm{e})$ in the same row indicate no significant differences between means $(p \leq 0.05)$

Same greek letter $(\alpha, \beta, \gamma)$ in the same column indicate no significant differences between means $(p \leq 0.05)$ 
Application of high-pressure processing induces modifications of TPA criteria, as

306 summarized in table 2. For samples at day 0 , hardness decreases significantly from $100 \mathrm{MPa}$

307 to $300 \mathrm{MPa}$ and remains constant after $400 \mathrm{MPa}$ and $500 \mathrm{MPa}$ treatment; cohesiveness,

308 springiness and resilience are almost constant, and gumminess and chewiness decreases from

309100 to $300 \mathrm{MPa}$ and increase after $400 \mathrm{MPa}$ and $500 \mathrm{MPa}$ treatment. Globally, TPA criteria

310 are diversely affected by high-pressure, and effect of high-pressure changes markedly around

$311300 \mathrm{MPa}$, in accordance with exudation and WHC results.

312 At day 0 decrease of hardness for samples treated at 100, 200 or $300 \mathrm{MPa}$, is in accordance

313 with results of Ashie and Simpson (1996) on bluefish, and differ from results of Anguspanish

314 and Ledward (1998) who observed an increase of cod fillet hardness for $400 \mathrm{MPa}-20 \mathrm{~min}$. In

315 regard to evolution of texture during storage, hardness does not change for 100 and $200 \mathrm{MPa}$

316 treated samples, it decreases the fourteenth day for $300 \mathrm{MPa}$, and it changes slightly for 400

317 and $500 \mathrm{MPa}$. Finally, we can assess than pressure treatment above $300 \mathrm{MPa}-5 \mathrm{~min}$ is

318 necessary to obtain after 7 or 14 days a hardness equivalent to the untreated sample at day 0 ,

319 and that samples treated at 100 or $200 \mathrm{MPa}$ do not evolve during storage.

320 Post mortem changes of fish texture are mainly caused by modifications of myofibrillar

321 proteins, due both to proteases action and to variation of physical and chemical conditions.

322 High-pressure treatment induces a reversible $\mathrm{pH}$ fall (Hayert and others 1999) and a

323 modification of hydrogen and hydrophobic bonds which brings about changes in protein

324 structure. Effect of high-pressure on fish texture ensues from these modifications of water

325 bond, protease activity, aggregation or gelation of myosin and sarcoplasmic proteins

326 (Anguspanish and Ledward 1998; Heremans 1982). 
The histological images of muscular fibres section are shown on the figure 4. Control

330 fibres at day 0 appear as shrunken cells, with a great extracellular space: this space is not the

331 result of gaping since preparation of sample is realized quickly after slaughtering. This

332 phenomenon is ascribed to the fixing and dehydration methods which could weaken links

333 between fibres and myocommata. Storage of fish fillets induces numerous cracks inside the

334 fibres, and a deterioration of pericellular connective tissue is visible after 14 days of storage.

335 This evolution of myofibrils structure is the result of natural degradation from proteases and

336 microorganisms. This observation is linked with evaluated hardness decrease during storage,

337 due to the action of proteases on collagen and myofibrillar proteins.

338 The fibres appearance is not changed when samples has been pressurized at $100 \mathrm{MPa}$.

339 From $200 \mathrm{MPa}$, the more the pressure treatment is high, the more the fibres look tightened

340 and round. The extracellular space decreases when pressure increases, in relation to the 341 compaction of muscle and the possible protein gel network formation. Moreover, the sample

342 preparation has less effect on extracellular spaces when the proteins began to form a gel.

343 Cheftel and Culioli (1997) reported that pressure above $200 \mathrm{MPa}$ often causes protein

344 gelation, whenever pressure and protein concentration are high enough. These observations

345 corroborate the increase of hardness observed at 400 and $500 \mathrm{MPa}$ : denser structure muscle 346 presents higher hardness values. Globally, the structure is not modified in comparison with

347 works of Gudmundsson and Hafsteinsson quoted by Bremner, 2002. From $200 \mathrm{MPa}$, we do

348 not observe any crack apparition during storage, and muscle remains more compact that for

349 control sample. Connective tissue presents an irregular distribution. Indeed the probable

350 proteases inactivation and the gelation of actomyosin above $200 \mathrm{MPa}$ lead to a good myofibrils structure preservation. 


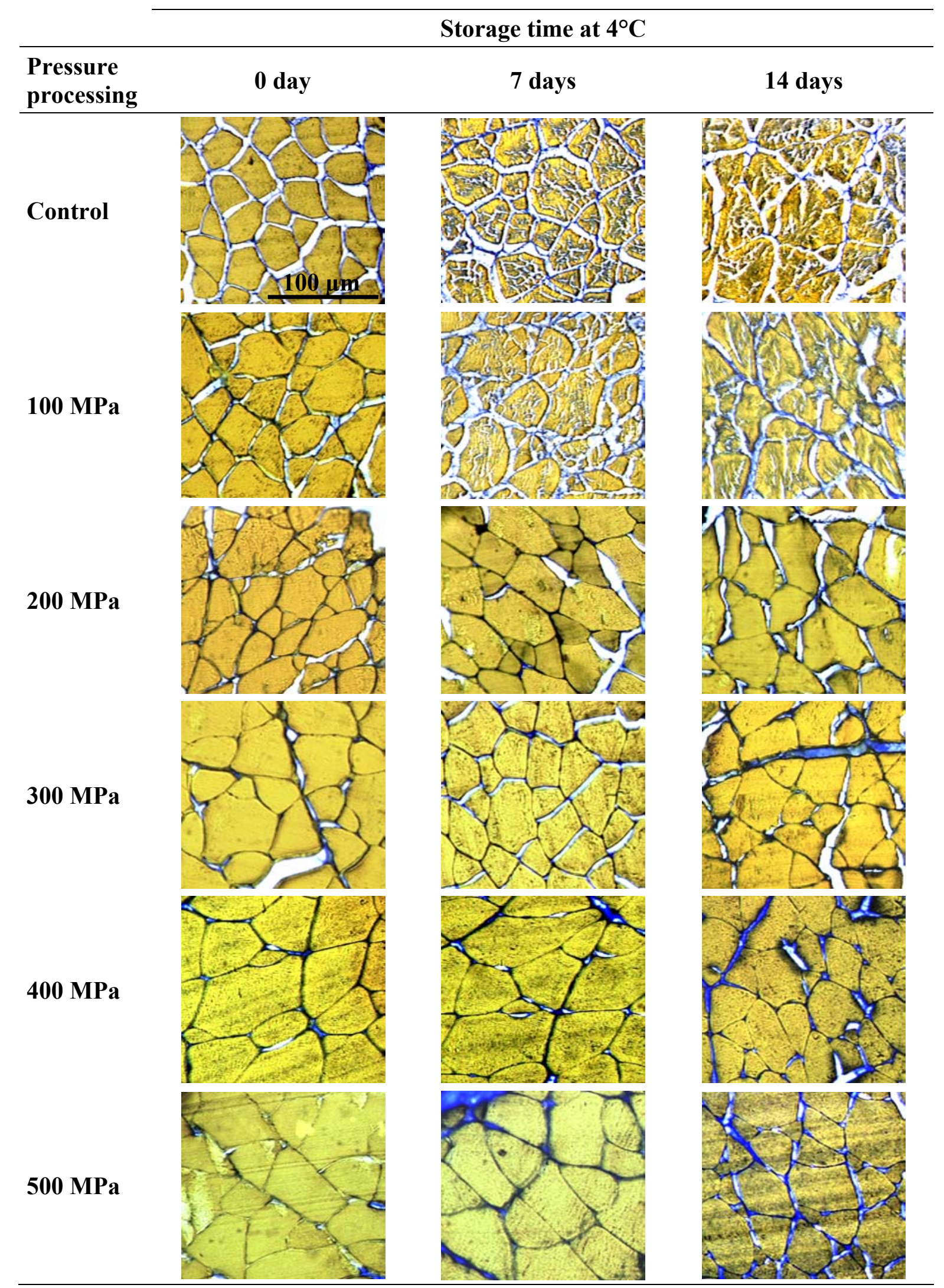

Fig. 4. Transverse sections of sea bass muscle treated by high-pressure processing and stored during 0,7 and 14 days at $4^{\circ} \mathrm{C}$. Muscle protein stains orange and collagen blue. 


\subsection{Impact of pressure processing on microbiological quality of fish muscle}

360 The microbial flora is present on the skin and in the digestive system of the living fish.

361 These micro-organisms contaminate the muscle after the fish dies. Thus in spite of hygiene 362 precautions, total aerobic count of untreated sample reached $10^{6} \mathrm{CFU} / \mathrm{g}$ at day 0 , and around $36310^{9} \mathrm{CFU} / \mathrm{g}$ after 7 and 14 days of storage at $4{ }^{\circ} \mathrm{C}$. These results are in accordance with data 364 from Food and Agriculture Organisation of the United Nations (Huss, 1995) reporting $10^{8}$ to $36510^{9} \mathrm{CFU} / \mathrm{g}$ of fish flesh.

366 Figure 5 shows a significant decrease of total aerobic count when pressure increases from 200 $367 \mathrm{MPa}$, reaching only $30 \mathrm{CFU} / \mathrm{g}$ for $500 \mathrm{MPa}$ treatment. These results confirm the effect of 368 high-pressure on the reduction of microbial growth (Cheftel, 1995), proving that high369 pressure treatment is a powerful tool to improve microbiological quality of fresh food. When 370 sample has been treated at $500 \mathrm{MPa}$, its total aerobic count after 7 days of storage is the same 371 that the one of control sample at day 0: the shelf life has been extended for one week. 372 However, whatever pressure treatment, at day 14, the total aerobic count reaches $10^{9} \mathrm{CFU} / \mathrm{g}$, 373 which is probably the maximal contamination. Then, we underscored that high-pressure 374 treatment above $300 \mathrm{MPa}$ improved microbiological quality of fish fillet for at least seven 375 days. 


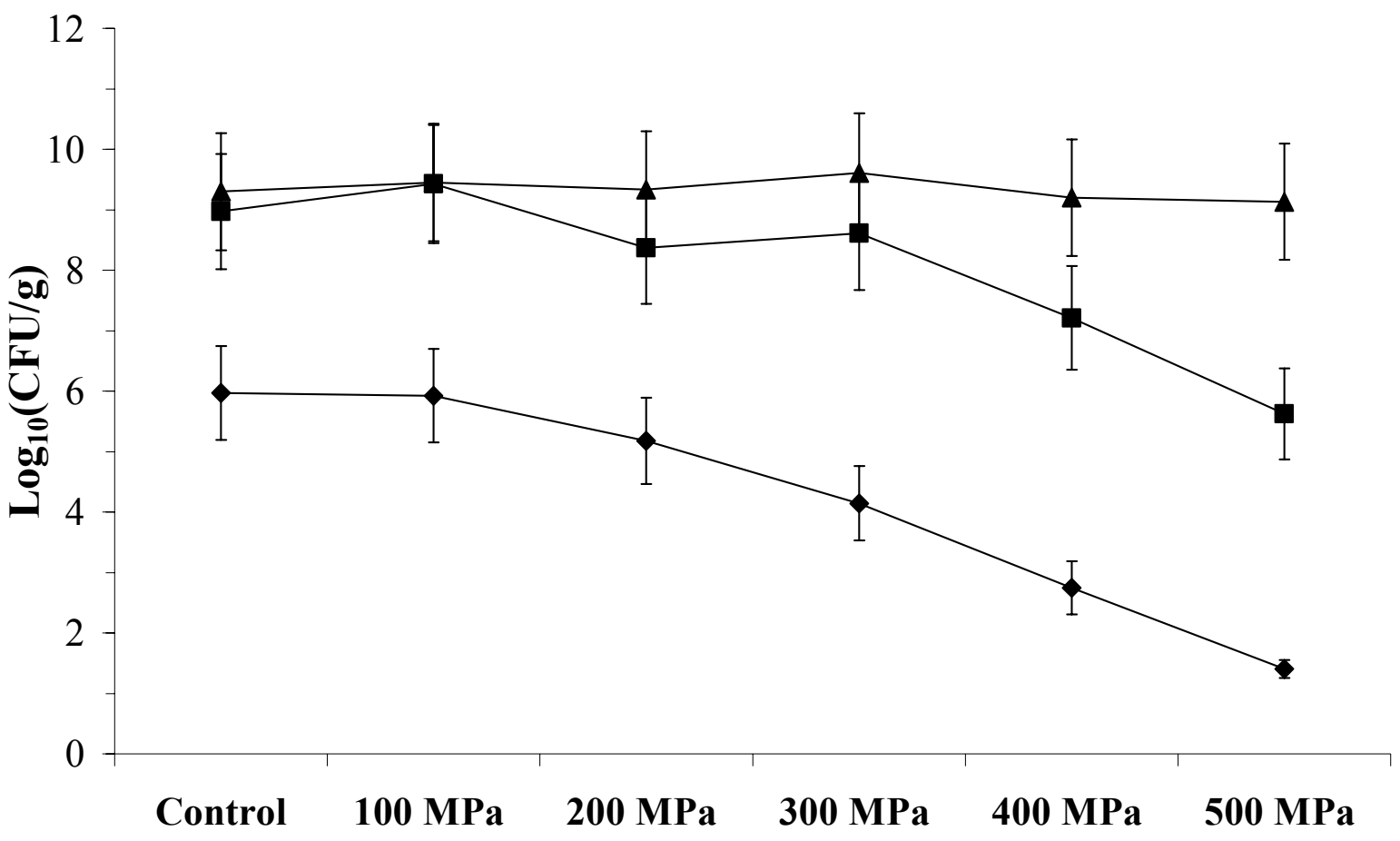

Fig. 5. Total aerobic count variation during storage at $4^{\circ} \mathrm{C}$ during $0(\diamond), 7(\square)$ and 14

\section{Conclusion}

384 Our results showed that the quality of the sea bass fillet can be improved by the high-pressure treatment and that we had a remarkable structural preservation. From a microbiological point

386 of view, high-pressure increases the shelf-life. Moreover above $200 \mathrm{MPa}$ high-pressure 387 decreases natural exudation, allowing an increase of the yield of net weight after storage. 388 Above $300 \mathrm{MPa}$ high-pressure treatment allows also to keep hardness of fillet in a good range 389 for consumer who rejects soft fish flesh. Nevertheless color of fish changes with high390 pressure treatment, but this difference probably vanishes after cooking: as fish is mainly eaten 391 after cooking, this drawback could be minor in comparison with the enhancement of 
392 microbiological and textural quality. Further studies on proteases and their behaviour under

393 pressure are necessary to understand the ageing of fish fillets after high-pressure treatment.

394

395 Acknowledgements

396 The authors are grateful to Sylviane Delépine for her technical assistance.

397 This work was supported by a grant from Ministère de l'Agriculture, de la Pêche, de 398 l'Alimentation et des Affaires Rurales (France).

399 


\section{References}

Ando M. 1997. The softening mechanisms of fish meat during refrigeration after death. Recent Res Devel In Agricultural and Food Chem 1: 49-59.

Angsupanich K, Ledward DA. 1998. High-pressure treatment effects of cod (Gadus morhua) muscle. Food Chemistry 63: 39-50.

Ashie INA, Simpson BK. 1996. Application of high hydrostatic pressure to control enzyme related fresh seafood texture deterioration. Food Research International. 29 (5-6): 569-575.

Ashie INA, Lanier TC, MacDonald GA. 1999 Pressure-induced denaturation of muscle proteins and its prevention by sugars and polyols. J. Food Sci. 64: 818-822.

Astier C, Labbe J-P, Roustan C, Benyamin Y. 1991. Sarcomeric disorganisation in post mortem fish muscle. Comparative Biochemistry and Physiology. 100 B: 459-465.

Bourne MC. 1978. Texture profile analysis. Food Technology 32: 62-66.

Bremner AH, Hallett CI. 1985. Muscle fibre connective tissue junctions in the fish blue grenadier (Macruronus novaezelandae): a scanning electron microscope study. J. Food Sci. 50: 975-980.

Bremner HA. 1992. Fish flesh structure and the role of collagen: its post mortem aspects and implications for fish processing. In: Quality Assurance in the Fish Industry. Huss H.H., Jakobsen M. and Liston J. Elsevier Sci. Pub. 39-62.

Bremner HA. 2002. Safety and quality issues in fish processing. Cambridge Woodhead Publishing Limited 507p.

Chapleau N, de Lamballerie-Anton M. 2003. Changes in myofibrillar proteins interactions and rheological properties induced by high-pressure processing. Eur. Food Res. Technol. 216:470-476.

Cheftel JC. 1995 Review : high-pressure, microbial inactivation and food preservation. Food Science and Technology International. 1: 75-90.

Cheftel JC, Dumay E. 1997. Les hautes pressions : principes et potentialités, Agoral, Tech. et Doc. Lavoisier Paris 197-213.

Cheftel JC, Culioli J. 1997. Effects of high-pressure on meat: A review. Meat Science. 46 (3) 211-236.

Dunajsky E. 1979. Texture of fish. Journal of Texture Studies 10: 301-318. 
Haard NF. 1992. Biochemistry and chemistry color and color changes in seafoods. In Advances in Seafood Biochemistry (eds, Flick, G.J. and Martin, R.E.) Technomic Publishing Co. Lancaster 305-360.

Hallett IC, Bremner HA. 1988. Fine structure of the myocommata-muscle fibre junction in hoki (Macruronus novaezelandiae). Journal of the Science of Food and Agriculture 44: 245-261.

Hayert M, Perrier-Cornet JM, Gervais P. 1999. A simple method for measuring the $\mathrm{pH}$ of acid solution under high-pressure. The Journal of Physical Chemistry. A, Molecules, Spectroscopy, Kinetics, Environment and General Theory 103: 1785-1789.

Heremans K. 1982. High pressure effects on the proteins and other biomolecules. Ann Rev Biophys Bioeng. 11: 1-21.

Huss HH. 1995. Quality and quality changes in fresh fish. FAO Fisheries Technical Paper, 348. Rome, FAO, 195p.

Jiang ST. 2000 Effect of proteinases on the meat and seafood quality. Food Science and Agricultural Chemistry 2(2): 55-74.

Knorr D. 1999. Novel approaches in food-processing technology: new technologies for preserving foods and modifying function. Current Opinion in Biotechnology. 10(5): 485-491.

Lavety J, Afolabi OA, Love RM. 1988. The connective tissues of fish. IX. Gaping in farmed species. International Journal of Food and Technology. 23: 23-30.

Montero P. 1997. Involvement of collagen and connective tissue in postmortem changes in seafoods. Evaluation of Fish Freshness. 12-14: 190-197.

Oshima T, Nakawa T, Kiozumi C. 1992. Effect of high pressure on the enzymatic degradation of phospholipids in fish during storage. In Blight EG. Seafood Science and Technology, Oxford, Fishing News Books, 64-75.

Oshima T, Ushio H, Koizumi C. 1993. High-pressure processing of fish and fish products. Trends in Food Science and Technology.4: 370-375.

Papa I, Alvarez C, Verrez-Bagnis V, Fleurence J, Benayamin Y. 1996. Post mortem release of fish white muscle $\alpha$-actinin as a marker of disorganisation. Journal of Science and Food Agriculture 72: 63-70. 
Papa I, Taylor RG, Astier C, Ventre F, Lebart MC, Roustan C, Ouali A, Benyamin Y. 1997. Dystrophin cleavage and sarcolemma detachement are early post mortem changes on sea bass (Dicentrachus labrax) white muscle. Journal of Food Science. 62: 917-921.

Rehbein H. 1997. Post mortem changes of sarcoplasmic proteins of flesh fish. Evaluation of Fish Freshness. 238-240.

Smelt JPPM 1998. Recent advances in the microbiology of high pressure processing. Trends in Food Science and Technology. 9: 152-158. 